\title{
LA DESAMORTIZACIÓN Y ENAJENACIÓN DEL DOMINIO DE SUECA A FINALES DEL ANTIGUO RÉGIMEN: LA PRESENCIA DE GODOY COMO DUQUE Y SEÑOR DE SUECA ${ }^{1}$
}

\author{
LUIS M. ROSADO CALATAYUd \\ Universidad de Valencia
}

Fecha de recepción: diciembre de 2009

Fecha de aceptación: febrero de 2010

El primero de enero de 1803 mediante un auto de otorgamiento Manuel Godoy consiguió añadir a la infinidad de cargos que ostentaba el de Señor de Sueca. El acceso a la propiedad de este señorío, gracias a un peculiar proceso de subasta, supondría adicionalmente un intento de «refeudalización» de las relaciones sociales de esta población, como consecuencia del cambio de jurisdicción. Cuando el 26 de marzo de 1808 los habitantes de Sueca conocieron, a través del Diario de Valencia, la noticia de la confiscación de los bienes de Godoy, y se apresuraron a celebrarlo, no podían suponer que el Real Decreto de Fernando VII, acabaría significando un largo pleito para la población que no se resolvería hasta muchos años después.

\section{LA EXPANSIÓN AGRARIA Y SU INCIDENCIA EN LA ESTRUCTURA DE LA PROPIEDAD DE SUECA. LA FUTURA POSESIÓN DE GODOY}

La titularidad del señorío de Sueca, después de diversos cambios había pasado a manos del rey, como Gran Maestre de la Orden de Montesa. Al producirse en 1592 la incorporación de la Orden de Montesa a la Corona, Felipe II pasó a ser Rey y Señor de Sueca. Mediante Bula del Papa Sixto V, se establecía la anexión de Sueca a la

\footnotetext{
1. Este trabajo está realizado al amparo de una beca para la formación de personal investigador con carácter pre-doctoral del Programa V Segles, concedida por la Universidad de Valencia.
} 
Mesa Maestral de la Orden². A partir de este momento, el rey, como Gran Maestre y Administrador Perpetuo de todos los bienes y rentas de la Orden, se convirtió en Señor en las tierras de la Orden ${ }^{3}$. Este cambio de titularidad provocó un mayor distanciamiento de Administrador y administrados. La condición absentista de la administración suscitaría, a lo largo de los dos siglos siguientes, diversos conflictos entre la monarquía, la Religión de Nuestra Señora de Montesa y San Jorge de Alfama, y el ayuntamiento, y los terratenientes y vecinos de Sueca, tanto en el orden gubernativo como en el contencioso.

Las funciones que anteriormente ostentaba el Maestre de la Orden pasaron a ser ejercidas por los lugartenientes, figura creada en 1615 por Felipe III, y que hasta mediados del siglo XVIII dispusieron de plenos poderes dentro de la Orden de Montesa ${ }^{4}$. El funcionamiento de la administración a lo largo del siglo XVIII puede calificarse de negativo, lo que con el transcurso del tiempo derivó en una devaluación de las rentas señoriales. Montesa se vio obligada a realizar cabreves ${ }^{5}$ en sus territorios para revisar y actualizar sus derechos y rentas. Por una Real Orden, promulgada por Fernando VI, en Aranjuez, el 18 de Septiembre de 1751, se comisionaba a D. Alonso Morón, como Juez Particular y Privativo, en calidad de Delegado inmediato a su Real Persona, para el examen y reconocimiento de los Bienes y efectos de la Mesa Maestral de Montesa. El monarca estaba informado de la notable decadencia a la que habían quedado reducidos los bienes y efectos pertenecientes a la Orden de Montesa -según se desprende de la copia del nombramiento- debido a las ventas y licencias para fabricar casas y rompimientos de tierras, que los lugartenientes generales habían concedido a particulares sin el control debido ${ }^{6}$.

2. ANDRÉS RoBRES, Fernando.: «La economía de la Orden de Montesa cuando la incorporación: Patrimonio, renta gasto, balances (1592-1602)». En Estudis. Revista de Historia Moderna. № 25, 1999, pp. 55-88

3. Aguado, A.: Propiedad Agraria y Transformaciones Burguesas. El Señorío de Sueca en la Crisis del Antiguo Régimen. Universitat de València. Ajuntament de Sueca. 1986. pp. 24.

4. Villarroya, José.: Real Maestrazgo de Montesa: Tratado de todos los derechos, bienes y pertenencias del patrimonio del Maestrazgo de la real y militar Orden de Sta. María de Montesa y S. Jorge de Alfama. Tomo I y II. Valencia. Oficina de Benito Monfort, 1787, pp. 106-108. El Padre Amado Burguera, cronista oficial de Sueca a principios del siglo XX, transcribe, en el documento número 84, una copia certificada del Archivo Histórico Nacional. (En adelante AHN.) en la que consta un privilegio de Felipe IV, del año 1657, por el que se hace donación a la Orden de Montesa de las tierras áridas de la Albufera de Valencia, confinantes con el término de la villa de Sueca. «...damos, donamos, cedemos, consignamos y adjudicamos a perpetuidad las dichas tierras secas y áridas, tanto por defecto como por retroceso del agua, y también por retroceso del lago...sean ya establecidas o no lo sean...» BURGUERA SERRANO, A. de C.: Historia fundamental documentada de Sueca y sus alrededores, en los aspectos geográfico, militar, político, civil, estadístico, religioso, moral, productivo, económico, filosófico, sociológico cultural, arqueológico, artístico y bio-bibliográfico; con notables ilustraciones. Valencia, 1921-1924, 2 Toms. Edició: 2000 (Sueca). Tomo II, pp.293-300.

5. Se trata de que el enfiteuta reconozca, a petición del censualista, que la finca y sus mejoras están sujetas a censo.

6. Archivo Histórico Municipal de Sueca (En adelante AHMS.) Hacienda: Ordres i Reglaments de Propis $i$ Arbitris. H-2. «Documentos de las Regalías de Propios 1752 a 1809» 
Alonso Morón comenzó a actuar con total diligencia, como lo prueba la presencia de diferentes copias de documentación del siglo XVII y principios del XVIII, todas ellas realizadas con papel timbrado del año 1752. Gracias a esta recopilación, el Archivo de Sueca dispone de documentos correspondientes a la Orden de Montesa relativos a los cabreves realizados en 1615,1700 y $1737^{7}$. Con motivo de estas revisiones tenemos conocimiento de las transformaciones que se produjeron en las tierras, pasando de los cultivos primigenios (vid, trigo y olivo), a la morera y el arroz. El incremento de la superficie cultivada se fue consiguiendo a costa de los terrenos ganados al lago de La Albufera y a las continuas transformaciones que sufrió el secano y el cultivo de la tríada mediterránea, debido a la extensión del regadío iniciada en el siglo $\mathrm{XV}^{8}$ En 1453 se produjo la apertura de la acequia de Cullera en el término de Sueca, y en el año de 1457 se otorgó el privilegio del rey Don Alfonso el Magnánimo, por el que sancionaba a favor de la población una prerrogativa mediante la cual los suecanos podían sacar la cantidad de agua que quisieran del río Júcar para regar sus tierras. Con estas medidas se establecían las bases del desarrollo económico y demográfico de este municipio.

El proceso de substitución de la producción agrícola tradicional por el nuevo cultivo del arroz comenzó a finales del XV. Aunque inicialmente se limitaba a tierras marginales en la frontera de la Albufera, fue favorecido por la extensión del regadío. La construcción de la «sèquia Major», se produjo en el siglo XVI y, posteriormente, ya en el Setecientos, con la apertura de la «Sèquia de Muzquiz»" (sèquia de Busques en la terminología popular), se conseguiría ampliar el termino cultivado a costa de La Albufera. Las especiales condiciones de inundabilidad en el entorno del lago y su escasa profundidad permitieron su transformación agrícola para el cultivo del arroz. La actividad arrocera, pionera del expansionismo agrario en las zonas húmedas, se fue extendiendo a costa de la paulatina reducción de la superficie del lago, especialmente a partir del siglo XVIII. ${ }^{10}$ Todo ello produjo una metamorfosis del paisaje y de

7. Cabreve de la Universidad de Sueca a favor de la Orden de Montesa en el año de 1615. Proceso de la Universidad de Sueca pidiendo licencia para cargarse un censo de 4.000 libras, concedido por el Maestre de Montesa en 1669. Cabreve de la Universidad de Sueca a favor de la Orden de Montesa de los Bienes sitios que posee en el año 1700. Cabreve de los Alcaldes y Regidores de la Universidad de Sueca a favor de la Mesa Maestral de la Orden de Montesa en el año 1737.AHMS. Fons Antics. Caixa 87. Documentos: LXXVI; LXXXVI; XCIV y XCVIII.

8. Desde el siglo XV se aprovechan las aguas del Xúquer mediante la utilización de los azudes de los "Quatre Pobles» y el de Cullera. Las aguas eran distribuidas por las acequias de Campanar, la Mayor de Cullera y la acequia Mayor de Sueca.

9. Miguel Muzquiz, Ministro de Hacienda, había obtenido en 1761 una concesión para el establecimiento de 10.000 hanegadas de tierra, con la apertura en 1764 de esta acequia y la conversión de las tierras en regadía, Muzquiz obtendría EN 1782 licencia real para cultivar arroz. SANCHIS IBOR, Carles.: Regadiu $i$ canvi ambiental a l'Albufera de València. Universitat de Valencia.2001. pp. 161-164.

10. La primera fitación de la Albufera se realizó en 1579 , y en 1761 se realizó una segunda que prácticamente coincidía con la anterior. Hasta ese momento, la desecación pudo obedecer exclusivamente a causas naturales. El procedimiento empleado para elevar el nivel del terreno y ponerlo en cultivo consistía en realizar, en primer lugar una mota o margen de tierra que sobresalía del nivel del agua, delimitando la parcela del resto del lago. Posteriormente, se acarreaba mediante barcas «albuferencs» el barro proce- 
las prácticas de cultivo y comercialización de la producción agrícola favoreciendo su orientación al mercado exterior.

El siglo XVIII supuso, económica y urbanísticamente, el período de mayores transformaciones en la localidad ${ }^{11}$, sentando las bases de la estructura económica, social y política de finales del Antiguo Régimen. A lo largo de toda la centuria, pero con un ritmo más acelerado en la segunda mitad, se produjeron los grandes establecimientos de tierras. La fórmula utilizada para poner en explotación las tierras incultas, los «establiments», por lo que se refiere al acceso legal a la tierra, es el contrato de enfiteusis. Es en estos momentos cuando comienza a identificarse como propietario al enfiteuta, al poseedor del dominio útil. Los campesinos acomodados y la oligarquía local protagonizaran en la primera mitad del XVIII enfrentamientos con la Orden de Montesa, lo que se traducirá en una mayor concesión de establecimientos a unos determinados grupos sociales más afines con el señorío.

Un claro reflejo de la rentabilidad del cultivo del arroz lo constituye la utilización por la Corona de las tierras de la Orden de Montesa para premiar fidelidades. Los mayores enfiteutas pasan a ser los miembros de la nobleza relacionados con la administración del gobierno, como Miguel de Múzquiz ${ }^{12}$, Cristóbal de Vilches, o la familia $\mathrm{Caro}^{13}$, que se constituyen como los principales beneficiarios de estas concesiones, junto con un reducido grupo de miembros de la élite de la capital de Valencia y en menor medida, con establecimientos de extensiones más reducidas, por algunos grupos de propietarios de las capas sociales medias ${ }^{14}$. Junto con las concesiones legales de establecimientos, también se produjeron ocupaciones ilegales de tierras llevadas a cabo por los vecinos de Sueca, especialmente en la primera mitad del siglo XVIII.

dente del fondo del lago y de los canales que desembocaban en él, hasta elevar lo suficiente el terreno en la parcela y hacerlo apto para el cultivo del arroz.

11. En la segunda mitad del XVIII, se produce la construcción de edificios emblemáticos como son la reedificación del Convento de Franciscanos, cuya primera piedra se colocó el 1 de Mayo de 1753, el matadero construido en 1776 o el edifico del Ayuntamiento que data de 1784.

12. Don Miguel de Muzquiz, Conde de Gausa, al que ya nos hemos referido, supone el caso más significativo. RIERA, Juan.: Estudios y documentos sobre arroz y paludismo en Valencia (Siglo XVIII). Valladolid. Universidad de Valladolid. 1982., pp. 80

13. La Familia Caro y Fontes, es otra de las que concentra un importante volumen de tierras, mediante una concesión de la Corona de fecha 30 de diciembre de 1761, D. Ventura Caro, teniente general de los reales Ejércitos y sus hermanos Carlos, Pascual y Pascuala, reciben 3.425 hanegadas, situadas todas en la frontera de Sueca. RIERA, Juan.: Estudios ...op, cit. p. 82. La concesión Real era teóricamente para un período de 20 años, si bien D. Buenaventura Caro y Caro, hijo de Ventura Caro y Fontes, aparece en el Padrón de Riqueza de Sueca de 1801 como terrateniente residente en Valencia, con una posesión de 548 hanegadas en las que se cultivaba arroz. AHMS. Padrón de Riqueza 1801. Terratenientes.

14. En 1787 los terratenientes residentes fuera de Sueca con una propiedad media superior a las 400 hanegadas suponen el 0,7\% del total, aunque la superficie global que poseen representa más del 20\% de la total. Entre los seis mayores propietarios forasteros poseen 11.560 hanegadas. MATOSES CUQUERELLA, Rafael., «L'establiment de terres a Sueca». En Quaderns de Sueca. Any 1984. Nº V.pp. 55-77. 


\section{Cuadro 1 \\ Los mayores establecimientos de tierras en los límites de la Albufera con la frontera de Sueca. $1771^{15}$}

\begin{tabular}{|l|c|c|}
\hline \multicolumn{1}{|c|}{ Terrateniente } & Lugar de Residencia & Extensión* \\
\hline Don Miguel de Muzquiz & Madrid & 5.457 \\
\hline Don Pascual Sánchis & Valencia & 4.010 \\
\hline Don Carlos Caro & Valencia & 3.425 \\
\hline Dr. Don Francisco Mieles & Valencia & 770 \\
\hline Don Pedro Turbe & Valencia & 600 \\
\hline Don Agustín Pinedo & Valencia & 469 \\
\hline Marqués de Jura Real & Valencia & 389 \\
\hline Ana María Sanz & Sueca & 330 \\
\hline Marín Ximeno & Valencia & 300 \\
\hline Francisco Rodenes & Sollana & 250 \\
\hline
\end{tabular}

*Extensión en hanegadas

Como puede apreciarse en el cuadro $\mathrm{n}^{\circ} 1$, entre los principales terratenientes propietarios de los nuevos establecimientos, únicamente encontramos a un vecino de Sueca ${ }^{16}$. No obstante, entre los grandes beneficiarios de la nueva situación, derivada de la favorable coyuntura comercial que proporcionaba la fuerte demanda del arroz y la consiguiente alza de los precios, además de a los propietarios forasteros, también encontramos a un reducido grupo de campesinos acomodados que conforman la oligarquía local. Labradores con posesiones que no dudan en incrementar el volumen de tierras en explotación mediante el arriendo a los miembros de la nobleza, el clero y la burguesía absentista, que a su vez subarrendarán a pequeños propietarios y jornaleros. Entre sus miembros encontramos los apellidos que veremos ocupando cargos relevantes en el consistorio y que protagonizan un ascenso social a lo largo de la segunda mitad de la centuria.

El arroz y la morera pasarían a ser los dos cultivos mayoritarios en el siglo XVIII, con un progresivo predominio del primero, que llega a ser hegemónico, sobre el segundo $^{17}$. Mediante un complejo, pero bien estudiado, sistema hidráulico que se extendía

15. Matoses CuQuerella, Rafael., op, cit, pp. 65.

16. «...siendo la mayor parte de los campos propiedad de los que viven en Valencia y varios pueblos, nunca los vecinos tienen bastante para vivir con decencia...» CAVANILLES, A.J. Obsevaciones sobre la Historia Natural, Geografia, Agricultura, Población y Frutos del Reyno de Valencia, II Vol. Madrid, 1795.1797. Vol. I., pp. 191

17. «...L'expansió de conreus oferia al segle XVIII, al terme de Sueca, unes grans possibilitats. Per una banda, timdrem l'aiguamoll situat als llindars de l'Albufera; per altra, diversos illots de terra dispersos pel terme. L'avenç de la terra conreada sobre l'erma, es realitza pausadament al llarg de la primera meitat de segle fins arribar a l'any 1760; des d'aleshores creix notablement...». MATOSES CUQUERELLA, Rafael, op, cit, 57-58. 
a lo largo del término, construido con notable esfuerzo por parte de los labradores, se posibilitaba que el líquido elemento alcanzara los puntos necesarios para que fructificara el arroz. De modo progresivo se produjo una importante trasformación del paisaje valenciano, en un tenaz afán por detraer al lago zonas aptas para el cultivo, previa la realización de la necesaria infraestructura constituida por: acequias, canales, escorrentías, azarbes..., que permitan drenar o aportar el agua necesaria para su cultivo. Palmo a palmo se reduce la superficie lacustre en un elevado porcentaje, que se transforma en tierra arrozal ${ }^{18}$. Este mismo tipo de operaciones se llevará a efecto en el resto de las zonas pantanosas valencianas, situadas en la Safor, la Costera, y las riberas del Xúquer y el Turia. Todo este esfuerzo permitiría conseguir una cosecha anual próxima a los 200.000 cahíces, según constató el botánico A. J. Cavanilles ${ }^{19}$.

Al finalizar la centuria del setecientos, se puede afirmar que el arroz constituye la base de la economía de la población. La superficie de cultivo, a pesar de las continuas prohibiciones y de las múltiples restricciones, a causa de las fiebres tercianas, seguiría creciendo fuera de los límites marcados por las autoridades ${ }^{20}$.

La anterior situación, provocó la retirada de los lugartenientes, cuyas competencias, especialmente en materia de nuevos establecimientos, acabarían pasando al Consejo de Órdenes. Por otra parte, la administración de las rentas, sería trasladada en 1750 a la Contaduría General ${ }^{21}$. Los intereses económicos de Montesa no sufrieron merma, antes bien al contrario, ya que la producción de morera y de arroz superaba en ingresos a la originaria de trigo, olivo y vid, si bien, tanto la partición de frutos establecida en los diferentes documentos de poblamiento, como los títulos de propiedad de particulares, ayuntamiento y común de vecinos no obedecían a la situación real.

18. A lo largo del siglo XVIII la extensión de La Albufera se vio reducida por la acción del hombre para la extensión del arrozal, aproximadamente se estima en 10.000 hectáreas la superficie ganada al lago durante esta centuria. SAla Giner, Daniel, CALERo, Francisco.: La Albufera de Valencia. Valencia, Ajuntament de València, 2000, pp. 23-29

19. Cavanilles. A. J. Observaciones ...op, cit, pp. 190-191

20. 14 de abril de 1753 Fernando VI promulgaba una Real Orden por la que se delimitaban, para cada población, las tierras en las que se podía cultivar el arroz, con la obligación de que fueran amojonadas, en presencia de las autoridades locales. En esta orden se solicitaban a los consistorios, donde el cultivo del arroz estaba permitido, la realización de estudios estadísticos en los que además de requerir las condiciones sanitarias, se debían aportar datos relativos al cultivo del arroz y a los precios del mismo. "...Estas tierras y las de cada pueblo en que se permita la cría de arroces en la Gobernación de Alcira, se han de amojonar en circuito con la presencia y asistencia del Gobernador de Alcira o de su Alcalde Mayor y con la intervención del Justicia del pueblo a quien pertenezcan, quedando razón puntual de todo en los libros capitulares y remitiéndoseme por dicho Gobernador las diligencias formales ejecutadas por ante escribano originales y una copia integra de ellas también firmadas y autorizadas, con expresión de las partidas de tierras en que se prohíbe y en que se permite la siembra de arroces y la extensión y hanegadas que cada una contenga ...» AHMS. Expedient D'acotament D'Arròs. Caixa Sp 1. 1753-1793

21. A partir de 1754 se volvió a crear la figura del lugarteniente, a los que el rey en 1761 facultó de nuevo para la concesión de establecimientos de tierras y licencias de venta. AguAdo, Anna.: Propiedad Agraria... op, cit, pp. 25-26 
La debilidad de los administradores de la Orden, la situación absentista del Señorío, y con posterioridad, la de los terratenientes forasteros, fue propiciando un mayor protagonismo de determinados sectores de la población, lo que, con el tiempo, acabaría siendo la práctica habitual en la estructura agraria de Sueca a lo largo de su historia. Estas circunstancias posibilitarían la consolidación de una importante oligarquía local de campesinos y propietarios agrarios, a los que ya nos hemos referido. Ante esta realidad, desde mediados del siglo XVIII, los diferentes Señores intentaron reforzar y actualizar el dominio directo de sus propiedades, ante la pujanza alcanzada por los enfiteutas en su intención de convertirse en los únicos propietarios de la tierra.

Por lo que se refiere a la estructura de los bienes del señorío, los derechos exclusivos, que permanecían en el XVIII en manos del rey -como Gran Maestre y administrador de la Orden de Montesa- eran: el derecho sobre las hierbas del término; el monopolio de la sosa; el control y, sobre todo la administración del agua de riego, que cada vez adquiriría una mayor importancia por la extensión del regadío. Respecto a los bienes de propios la Mesa Maestral y el Ayuntamiento mantenían un pleito desde 1753, por las discrepancias en el reconocimiento de los Derechos Dominicales. Mediante una Real Resolución de 31 de marzo de 1753, el Ayuntamiento se había visto obligado a aceptar la concesión en precario de los bienes de propios, ya que los títulos de compra que se habían exhibido a requerimiento del Juez Comisionado de Apeo y Deslinde, no se habían considerado suficientes ${ }^{22}$. Las regalías que en 1802 seguía administrando en precario el consistorio suecano constituían la principal fuente de ingresos de la hacienda local.

La peritación que sirvió de base para la subasta y posterior compra, fue calculada para el conjunto de regalías y derechos pertenecientes al Maestrazgo, de acuerdo con las rentas medias obtenidas en los últimos cinco años. Los rendimientos anuales se estimaron en 19.487 libras $^{23}$, sobre las que se estableció el valor total del señorío, calculando una rentabilidad del 5\% anual, en 389.440 libras $^{24}$.

22. AHMS Real Resolución de 31 de marzo de 1753. Hacienda: Ordres i Reglaments de Propis i Arbitris. H-2. «Documentos de las Regalías de Propios 1752 a 1809»

23. Esta cantidad resulta incluso inferior que la referida exclusivamente a la partición de frutos. Las rentas medias anuales, por este concepto, durante el período comprendido entre 1797 y 1801 se elevaron a 21.606 libras. La media anual correspondiente al producto de los arrendamientos de las regalías, en el decenio previo a la adquisición de Godoy (1792-1802), había ascendido a 10.963 libras. Hay que aclarar que hasta febrero de 1800 las rentas se consignaron en libras, moneda de Valencia, y que a partir de marzo de ese mismo año en Reales de vellón. [Escrito de Martín de Garay, Contador del Ejército en Valencia a Dn. Ignacio Abadía. Contador General de las Órdenes Militares de fecha 14 de julio de 1800. Archivo del Reino de Valencia (En adelante ARV). Clero. (Montesa). Leg. 945 Caja 2501. Relaciones para la Corte (relaciones mensuales de ingreso de caudales para la Contaduría General). Sueca Año 1800]. Este cambio de moneda no se consideró en el trabajo que sobre esta cuestión realizó Anna Aguado en 1981, por lo que las cantidades referidas al período comprendido entre 1800 y 1805 aparecen erróneamente elevadas. AGUADO, Anna. «La partició de fruits i la seua evolució a la segona meitat del segle XVIII a Sueca». En Economia Agrària i Història Local. I. Assemblea d'Història de la Ribera. València. Institució Alfons el Magnànim. 1981. pp. 363-381

24. La cantidad exacta correspondiente al 5\% de 19.487 libras es 389.740 libras, aunque la que aparece en la documentación es la de 389.440 libras. Declaración de los Peritos nombrados para el deslinde y tasación en venta de los bienes, regalías y derechos pertenecientes al Maestrazgo de Nuestra Señora de Montesa 
El 22 de noviembre de 1802, Sueca pasó a depender, mediante compra, de Manuel Godoy. El cambio de titularidad del señorío traería aparejado un proceso de señorialización de la mano del Duque de Sueca. La noticia no se conocería oficialmente por la población hasta el 22 de enero de 1803, por una carta de aviso de Cayetano de Urbina «Señor Intendente de este Exército y Reyno», fechada en Valencia el día anterior y dirigida al Señor Alcalde Mayor, en la que le anunciaba que el Gobernador del Consejo D. Josef Eustaquio Moreno, le había conferido amplias facultades para que diera posesión «a la parte del Excmo. Señor Príncipe de la Paz de esa villa contra Jurisdicción no solo la llamada Alfonsina, sino la suprema Varonal y demás Rentas, Fincas, Derechos y Privilegios, que en ella pertenecieron al Maestrazgo de Montesa». Así mismo, le informaba que «en el día de mañana» se desplazaría a Sueca con «los Señores o Señor apoderado que represente a la Persona del Exmo. Señor Generalísimo Príncipe de la Paz,». El Ayuntamiento reunido en cabildo acordó «obedecer cuanto sea, esperar sus órdenes... y prestarle el debido vasallaje..${ }^{25}$

El proceso que llevó hasta esta situación, en la que el patrimonio de Manuel Godoy se vio nuevamente favorecido, hay que entenderlo como una muestra más de la excepcional generosidad con la que los monarcas premiaron al Príncipe de la Paz. La amistad de Carlos IV y la reina María Luisa hacia el favorito, se traduciría en una rápida sucesión de ascensos militares, a los que se acompañaría los más elevados honores cortesanos. Los reyes colmaron de cargos y donaciones a Godoy, especialmente de propiedades territoriales ${ }^{26}$, alguna de las cuales comportaba la posesión jurisdiccional, como es el caso que nos ocupa. ${ }^{27}$

y S. Jorge de Alfama en la villa de Sueca. Año 1802. ArChivo GenERAL DE SimanCAS (En Adelante AGS.) Dirección General del Tesoro, inv. 24. legajo 310. folleto 38. Sin foliar.

25. Acuerdo de 22/01/1803. AHMS. Secretaria. Plens. Municipals. Sec. 11. 1801 a 1804.

26. Godoy consiguió los derechos del lago de la Albufera, la dehesa y tierras adyacentes, con todas las regalías y usos y apoderamiento, que eran entre otros: las hierbas, pastos, brozas, cañas, caza, riego, caminos, edificios de la iglesia de El Palmar, la casa llamada del Rey y otras, el diezmo entero y primicias en las tierras novales y el tercio diezmo en las antiguas, con la partición de frutos en unas y otras, los censos a que están sujetas, derechos de fadiga, luísmo, quindenios y demás enfiteúticos, el quinto diezmo de los pescados recogidos en el lago y el tercio de los conseguidos en el mar y la jurisdicción civil y criminal, alta y baja, mero y mixto imperio. Los derechos sobre el Lago de la Albufera abarcan también la Dehesa y tierras circundantes. «Esta finca fue adquirida por Godoy al Monarca mediante permuta con el Cortijo de San Isidro en Aranjuez...La valoración que se daba a esta finca de la Albufera en el Expediente del Tribunal Arbitraje, era de 27.723.000 R.v. y con un rendimiento anual de 1.108.920 r. v.». BELMONTE DíAZ, J. y LeSEDUARTE GIL, P.: Godoy. Historia documentada de un expolio. Ediciones Beta III Milenio S.L. Bilbao. 2004. pp. 126 y 463.

27. Del mismo modo que Godoy se convirtió en señor de la Albufera, con idénticas prerrogativas a las anteriores del rey y, como indica el decreto de permuta debía reconocérsele «dueño y propietario de ella y legítimo poseedor, contribuyéndole con sus rentas y rendimientos», conseguiría, mediante adquisición, amplios privilegios sobre el Señorío de Sueca. LA PARRA, E.: Manuel Godoy. La aventura del poder. Barcelona. Tusquets. 2002, pp. 257-258. 


\section{LA PARTICULAR DESAMORTIZACIÓN DE LOS BIENES DE LA ORDEN DE MONTESA Y LA ENAJENACIÓN DE SUECA A FAVOR DE GODOY}

Las gestiones que hicieron posible el acceso a la propiedad del Señorío de Sueca por Manuel Godoy se iniciaron en 1798. No obstante, la situación que formalmente lo había originado era muy anterior. España tenía abiertos dos frentes, el primero en el continente europeo, y el segundo en ultramar, que afectaba de lleno a las colonias españolas. El dilatado proceso conflictivo estaba abocando a la quiebra técnica de la Hacienda Real. Las distintas emisiones de «Vales Reales», que desde 1780 trataban de aplazar la difícil situación hacendística, devenían en una mayor carga, ya que había que hacer frente al pago de los intereses, con lo que el remedio adoptado estaba empeorando la situación económica del Estado. La desamortización se presentaba como una medida «extraordinaria» que trataba de paliar el importante déficit de la Hacienda Real, agravada en estos años por los enfrentamientos bélicos con Francia y con Inglaterra. A mayor abundamiento, el alza en los precios y la pérdida del poder adquisitivo de importantes sectores del campesinado, tanto de los arrendatarios, como de los jornaleros, e indirectamente de los artesanos, -a lo que hay que añadir los condicionantes propios del Antiguo Régimen, dado el importante número de privilegiados exentos del pago de impuestos- limitaban las posibilidades recaudatorias.

Es en este contexto en el que debe inscribirse el proceso conocido como la Desamortización de Godoy, que supuso sacar a la venta un volumen importante de bienes pertenecientes a «manos muertas» eclesiásticas, de los que las propiedades de obras pías fueron las primeras en salir a subasta. Más que una desamortización, como señala Joaquín Azagra, fue el resultado de un conjunto de desamortizaciones. En 1798 se emitieron tres decretos que señalaban como bienes enajenables aquellos que representaban dotaciones para fines determinados. ${ }^{28}$

Se plantearon las primeras operaciones desamortizadoras que afectaban a los bienes de los jesuitas, incautados tras la expulsión y los de las Órdenes Militares. Estas medidas fueron adoptadas por el propio Godoy y Miguel Cayetano Soler, Secretario de Estado y del Despacho Universal de Hacienda. No obstante, aunque la decisión vino motivada por las apremiantes necesidades de la hacienda, resulta difícil saber si en aquel momento se fue consciente de lo que iba a suponer a largo plazo esta decisión, ya que se estaban dando los primeros pasos para transformaciones futuras. Se atacaba a uno de los pilares fundamentales del Antiguo Régimen: la Iglesia.

Inicialmente se había determinado la conveniencia de sacar a la venta bienes de los maestrazgos de las cuatros ordenes, Alcántara, Calatrava, Montesa y Santiago. En 1798 Carlos IV, como Gran Maestre de la Orden de Montesa, había solicitado las oportunas autorizaciones para poder proceder a su enajenación, que fueron concedidas en

28. Según cuantifica Josep Fontana, el total de los bienes que se vendieron en el decenio 1798-1808 representan un volumen de unos 1.653 millones de reales, lo que equivale al $40 \%$ del valor de las ventas de la desamortización de Mendizábal. Fontana LÁzAro, J.: Revolución liberal, La. Política y Hacienda en 1833-1845. Instituto de Estudios Fiscales. Madrid. 2001, pp. 12. AZAGRA, J.: op. cit.. Nota 22, pp. 34. 
ese mismo año, por el papa Pío VI, quien comisionó al Cardenal Antonio de Sentmenat, en calidad de administrador de las órdenes militares, para que concediera el indulto. No obstante, Carlos IV, pese a disponer del permiso papal desde 1798, demoró hasta 1802 la emisión de la Real Orden al Cardenal Patriarca Sentmenat, comunicándole que subsistían los mismos urgentes motivos que impulsaron la impetración del breve, obteniendo así la correspondiente autorización para proceder a la enajenación de los bienes. Por un Real Decreto de 19 de abril de 1802, se comisiona a D. José Eustaquio Moreno, para poner en marcha una prueba sacando a subasta un señorío de cada una de las Órdenes Militares: Gata de Alcántara; Manzanares de Calatrava; Sueca de Montesa y Vebes de Santiago.

En el Breve Papal, de fecha 21 de julio de 1798, se daban instrucciones concretas en relación con la designación de las fincas que debían garantizar las cargas espirituales. Pero esta exigencia no fue tenida en cuenta. Carlos IV comisionó al Gobernador del Consejo para que realizara el remate de los bienes, expresando el monarca su voluntad de que se «empezase la operación por vía de ensayo por las propiedades de Sueca $»^{29}$. Las instrucciones prescribían que se actuara con la mayor brevedad, e incluso «se mandó la habilitación de los días feriados para la práctica de las diligencias». Se mandó fijar los edictos para la venta, y contrariamente a los intereses del erario público, se aplazó la liquidación de los bienes, efectos y derechos comprendidos en el Señorío. Este tipo de medidas acabaron determinando un menor importe de tasación, y consiguientemente de la venta.

Manuel Godoy conocía las posibilidades económicas de la Encomienda de Montesa, y Sueca resultó ser la propiedad más productiva de los bienes de este Maestrazgo. Además, el favorito de Carlos IV, disponía de información sobre la situación del Señorío, ya que estaba en posesión de la Albufera, la que había permutado al propio monarca ${ }^{30}$. De acuerdo con las indicaciones reales, se confirió una excepcional

29. El Breve Papal que comisionaba al Cardenal Patriarca, Antonio de Sentmenat y de Cartellà, prelado doméstico del Papa, limitaba la venta a que se realizaran las reservas necesarias y suficientes para que se pudieran cumplir las obligaciones que los maestrazgos tenían contraídas. Asignando las fincas que habían de responder de las cargas espirituales. Breve del Papa Pió Sexto de 21 de Julio de 1798, por el que se concedía al Rey facultad para enajenar rentas, fincas y derechos de los Maestrazgos de las cuatro órdenes militares de Santiago, Calatrava, Alcántara y Montesa. Instrucción Para los Sres. Diputados a Cortes de la Provincia de Valencia, que quieran defender la petición que la villa de Sueca hace á la Asamblea Constituyente, sobre su Señorio, que compró el valido Don Manuel Godoy, en 1803 y debe ser comprendido en la resolución que las Córtes acuerden respecto de todo lo que fue caudal de dicho Valido. Valencia. Imprenta Comercial. 1855. AHMS. Fons Antics. 321. 1813-1859.

30. El término de Sueca limita con la ciudad de Valencia por el norte, sirviendo La Albufera como frontera. En un manuscrito inédito del archivo del ceramista Manuel González Martí, se recoge la descripción de la cacería celebrada en la Albufera el 25 de noviembre de 1802, festividad de Santa Catalina, en la que participaron Carlos IV y Doña María Luisa con los príncipes y el favorito Manuel de Godoy: «Luego después de la comida le hicieron una larga explicación al Rey de lo que valía la Albufera, y de todas las fronteras de la Albufera, y de los productos de las cosechas de Arroz. Entonces le dijo el Rey a Godoy: Esto es lo que tú querías y decías que era una cosa que no valía nada...» Historia de Valencia del Cid por un testigo ocular (Pablo Carsí). Manuscrito inédito, propiedad de don Manuel González Martí. En 
celeridad a las formalidades del proceso de subasta: tasación, pregones y diligencias, que se realizaron en apenas 5 meses. El condicionado establecido para la venta limitaba las prerrogativas del nuevo comprador respecto de las que gozaba el Rey como Administrador Perpetuo y Gran Maestre de la Orden de Montesa.

La superficie estimada por los peritos nombrados para el deslinde y tasación de los bienes, fue fijada en 28.000 hanegadas, de las que 14.000 corresponderían al cultivo de arroz; 10.200 destinadas a huerta con moreras; 1.200 de tierra de secano con algunas viñas y olivos, y las restantes 2.600 hanegadas se consideraban incultas. Según el Padrón de Riqueza de 1801, la superficie destinada a los diferentes tipos de cultivo del término de Sueca superaba las 60.000 hanegadas $^{31}$. Este importante desequilibrio, por lo que se refiere a la extensión del señorío, fue determinante para el precio de compra. A lo anterior habría que añadir el importante desfase en la actualización de las rentas, debido a la escasa validez de los cabreves realizados a lo largo del XVIII para la fijación de la propiedad, como queda evidenciado por los sucesivos conflictos entre los vecinos y terratenientes de Sueca y con la Mesa Maestral de la Orden de Montesa ${ }^{32}$. La tasación realizada por los peritos, de acuerdo con las rentas percibidas en los últimos cinco años, se estableció en 389.440 libras, moneda de Valencia ${ }^{33}$, es decir 5.846.100 reales de vellón.

Con el fin de dar cobertura legal al proceso, una vez realizada la tasación se procedió a dar publicidad a la operación: aparición de los edictos en la Gaceta de Madrid y en Diario de Valencia, así como la fijación de los mismos en la ciudad de Valencia y pueblos de su Intendencia. Se concedieron los preceptivos 30 días para la recepción de ofertas, es decir hasta el 8 de noviembre de 1802, fecha en que se debía realizar el remate. Tres días antes de finalizar este plazo, el 5 de noviembre, Antonio Noriega de Bada $^{34}$, «apoderado del Excmo. Sr. Príncipe de la Paz, Duque de Alcudia, Grande

Momblanch y Gonzalbez. F. de P.: Historia de la Albufera de Valencia. Ayuntamiento de Valencia. Valencia. 2003, pp. 126-127.

31. El Padrón de Riqueza de 1801 fija en 61.632 hanegadas la superficie cultivada por vecinos y terratenientes en Sueca. AHMS. Padrón de Riqueza de 1801. Por lo que se refiere a las tierras destinadas al cultivo del arroz, Carmen García Monerris, facilita para el año 1761 un total de 22.186 hanegadas situadas en la frontera de la Albufera, correspondientes al término de Sueca. GARCIA MonerRIs, C. Rey y Señor. Estudio de un realengo del País Valencia. La albufera 1761-1836 Valencia. 1985. pp. 147-164.

32. Rosado CAlatayud, Luis: «El último pleito de la Mesa Maestral de la Orden de Montesa contra el Ayuntamiento y el Común de vecinos y terratenientes de Sueca. (1752-1803)» En Actes de les I Jornades d'Història Comarcal: Gènesi i elements configuradors. Alfara del Patriarca 15 i 16 juny 2009. CEU Cardenal Herrera. (En prensa)

33. AGS. Dirección General del Tesoro, inv. 24. legajo 310. folleto 38. Sin foliar. Esta tasación suponía aceptar por buenas las rentas de los últimos cinco años, si bien las mismas presentaban importantes incumplimientos de pago. Además, según el Padre Amado en la tasación no se contabilizó correctamente la superficie cultivada. «Esta cifra es del todo inexacta, pues había más del doble de hanegadas». Burguera Serrano, A. de C.: Op. Cit... T. II, pp 148-149.

34. En el proceso de desvinculación de la Villa de Sueca del Gran Maestrazgo de Montesa, aparecen situaciones en las que determinadas personas, no dudan en utilizar los cauces oficiales para asuntos de índole particular. Una prueba de lo anterior la constituye el hecho de que Antonio Noriega de Bada, que actúa en 
de España de primera clase» presentó su postura, si bien aprovechó para incorporar nuevas disposiciones, que acabarían determinando una modificación de las cláusulas originales que regían la venta ${ }^{35}$.

Antonio Noriega en nombre de su representado, con el fin de que la venta de dicha villa se materialice y cumpla de un modo que evite para en lo sucesivo toda duda y litigio, establecía en la plica importantes modificaciones, que venían a significar un cambio sustancial en las condiciones de la posesión del señorío. Entre otras cuestiones, se pedía que el comprador quedara liberado de toda pensión, carga y responsabilidad con respecto a la Orden de Montesa y a cualquier otra, y de modo especial las cantidades que anualmente se destinaban a la manutención, culto divino y limosnas del Sacro Convento. Los frutos, rentas, productos y rendimientos obtenidos por la Villa de Sueca y su término, debían de quedar libres de cualquier carga y obligación. Quedando el Gran Maestrazgo como responsable de la manutención y de las demás necesidades. Se solicitaba que se ratificara y confirmara en favor del comprador el dominio y dispensación de la aguas. Jurisdicción, distribución y administración económica de las mismas; en idénticas condiciones a las que tenía el Gran Maestre de Montesa en virtud del privilegio concedido por Alfonso El Magnánimo en $1457^{36}$. La principal fuente de riqueza del señorío la constituía el cultivo de arroz, por lo que la posesión del control del riego determinaba una total dependencia de los labradores. El dominio del agua sin duda permitiría modificar al alza sus futuras percepciones de rentas.

Una de las modificaciones con mayor significación fue la del cambio de jurisdicción. Noriega, atendiendo los deseos de Godoy, no dudaba en pedir para el comprador y sus sucesores, no sólo la jurisdicción Alfonsina, sino la jurisdicción suprema Baronal, en dicha villa y su término. De modo que pudiera nombrar juez privativo con jurisdicción civil y criminal, mero y mixto imperio, para conocer todas las causas que se promoviesen en primera instancia. Se solicitaba que esta concesión adquiriera la condición de hereditaria, para lo cual se pedía la expedición de los correspondientes Reales Decretos. La ampliación en la potestad que se solicitaba para el futuro señor de Sueca, pasaba por la necesidad de que se perpetuara el juzgado de apeo y deslinde, hasta que finalizaran y se efectuaran los recursos pendientes de esta naturaleza referi-

calidad de apoderado de Godoy, para la presentación de la postura, es además de «Caballero pensionado de la Real y distinguida Orden española de Carlos Tercero» miembro del Consejo de S. M. en el Real de Hacienda y su Tesorero General». Noriega es la persona responsable de recibir el pago, que él mismo, en calidad de apoderado, debe realizar por el remate de la operación.

35. AHMS. Secretaria. Plens. Municipals. Sec. 11. 1801 A 1804. En el Acuerdo de fecha 24/01/1803, se incorpora una copia de fecha 17 de enero de 1803 de la Contaduría Principal del Ejército de Valencia, firmada por Agustín del Llano, que a su vez, es copia certificada por D. Bartolomé Muñoz de Torres, escribano de Cámara y Gobierno del Consejo, de fecha 20 de Noviembre de 1802, del original firmado en Madrid el 5 del mismo mes, por el Excmo. Sr. D. Antonio Noriega de Bada. Original en AHN. Órdenes Militares, Consejo de Órdenes. Leg. 2171.

36. Como reconoce en su escrito el propio Noriega, en las condiciones originales no se hacía mención al «dominio de las aguas, jurisdicción en ellas y distribución y administración canónica de las mismas.» AHMS. Secretaria. Plens. Municipals. Sec. 11. 1801 A 1804. 
dos a Sueca y su término. Esta petición llevaba aparejada la condición de que contra las sentencias no se pudiera admitir ningún recurso de apelación, suplicación, revisión, ni de cualquiera otra naturaleza. Se solicitaba expresamente que se expedirán las competentes Reales Órdenes al Juez de Comisión ${ }^{37}$.

Se pedía una declaración en favor del comprador de todas aquellas prerrogativas de las que disfrutaba el Gran Maestrazgo, es decir los privilegios, bulas, gracias, definiciones, capítulos generales, órdenes reales y todas las preeminencias, bienes, derechos, títulos y acciones. De tal modo, que el comprador dispusiera de todas las ventajas y beneficios legales, o de derecho que estaban concedidos al Rey como Administrador Perpetuo y Gran Maestre de la Orden de Montesa en la villa de Sueca y su término.

En materia económica, Noriega en nombre de Godoy, solicitaba que todas las rentas que hubiesen vencido desde el $1^{\circ}$ de enero de 1802 y que no se hubieran ingresado en la Tesorería del Ejército en Valencia, pasaran a pertenecer al comprador ${ }^{38}$. Fijaba el importe de la postura por un precio colectivo y general, por todas las pertenencias, dominios, títulos, facultades, derechos, acciones, jurisdicción suprema, civil y criminal, privilegios preeminencias, y beneficios legales pertenecientes al Gran Maestrazgo para la administración y conservación de la Villa de Sueca y su término en 5.500.000 reales de vellón, a satisfacer del siguientes modo: 2.750 .000 reales en metálico y la otra mitad en Vales Reales ${ }^{39}$.

Finalmente se solicitaba que todas estas modificaciones, se consultaran y fueran sancionadas por el Rey mediante el correspondiente decreto de validación.

Este nuevo clausulado, en la práctica, venía a dotar la venta de las mismas prerrogativas que un señorío jurisdiccional, cuando en puridad la operación, de acuerdo con el planteamiento inicial, debería gozar exclusivamente de las ventajas de una propiedad privada.

37. Esta modificación resultaba especialmente importante en el Señorío por la gran cantidad de pleitos relativos al dominio directo, y que se estaban tramitando en Valencia, entre ellos los referidos al propio ayuntamiento.

38. La razón aducida para aplicar esta medida era la de «evitar molestas liquidaciones y prorrateos en los censos enfitéuticos y otro tipo de pagos, ya que estos se hacían por uno, dos o más años a diferentes plazos «pues por su incertidumbre, dificultosa liquidación y aventurada ejecución, ni pueden estimarse ni hacer parte de este contrato.»

39. Sobre los Vales Reales se había establecido por ley una diferenciación entre el valor nominal y el valor real. En las subastas la aportación en metálico suponía un 33\% más que si se realizaba en vales reales. Según señala Joaquín Azagra: «La instrucción de enero de 1799 y la adición posterior de diciembre del mismo año, identificaba de hecho el valor del papel en dos tercios del metálico; este valor funcional se aplicaba automático en las subastas...las oscilaciones que sufrió la cotización de los Vales Reales fueron demasiado acusadas -Hamilton las sitúa entre unos márgenes del 30 hasta el 70 \% por debajo de su valor facial, tras la asignación del curso forzoso que se produjo en 1799...» AzAGRA, J.: La Desamortización de Godoy en Valencia (1799-1807). IVEI. Institució Alfons el Magnánim. Valencia. 1986. Nota 17 pp. 28. Richard Herr llega establecer el año 1802 como el de mayor depreciación de los vales reales, que se cotizan al 75\% bajo la par «muchas personas rehusaban dar dinero en metálico por ellos a cualquier precio». HERR, Richard.:España y la Revolución del Siglo XVIII. Aguilar. Madrid. 1988, pp. 331 


\section{EL SEÑORÍO DE SUECA BAJO LA POSESIÓN DE MANUEL GODOY}

El Rey promulgó un Decreto Real por el que aprobaba el remate de la venta en favor del Príncipe de la Paz. Carlos IV, para evitar en lo sucesivo las dudas que pudieran ocurrir en esta venta y condescendiendo con los deseos del comprador, sancionaba todas las modificaciones introducidas por el comprador en su postura de 5 de noviembre ${ }^{40}$. Así mismo, eran aceptadas el resto de las alteraciones que la postura había introducido respecto de la plica original de la subasta, confiriendo al comprador los mismos privilegios que disfrutaba el Gran Maestrazgo, en cuanto sean más útiles para la amplia posesión de esta Villa y su término ${ }^{41}$.

De acuerdo con el contenido del Real Decreto Godoy entró en posesión del Señorío de Sueca, con todas las prerrogativas que había solicitado su apoderado en la presentación de su oferta, con lo que se confirmaba su poder señorial, otorgándosele la plena jurisdicción, control sobre las aguas «dominio, jurisdicción, administración y distribución de sus aguas», así como la imposibilidad de apelar las sentencias del tribunal de apeo y deslinde, administración y control de las regalías, que hasta ese momento disfrutaba en precario el ayuntamiento como bienes de propios.

Sueca, como ya se ha comentado, se había beneficiado de la condición absentista de Montesa, lo que permitía que la gestión municipal funcionara de un modo bastante autónomo. Aunque los efectos de los Decretos de Nueva Planta, habían significado la perdida de cierto grado de la independencia de que disponían los órganos de gobierno municipales, ya que mediante una Real Resolución de 1723 responsabilizaba a los señores de los nombramientos de ofíciales de los lugares de sus señoríos, en el caso de que estos no tuvieran todavía una influencia clara en este punto ${ }^{42}$. Esta disposición provocó cambios en la configuración de los órganos de gobierno. Desaparecía el Justicia, y los Jurats, que eran reemplazados por dos Alcaldes y por cuatro Regidores y no se hace mención a los consellers, ni a la Asamblea General, que quedan suprimidos. Sueca pasó a depender administrativamente del Corregidor de Alcira, delegado del Gobernador.

El sistema de elección de cargos se vio modificado. A lo largo del siglo XVII la dotación de cargos se realizaba por insaculación. Por una Real Resolución de 1723 se

40. «...declaro que verificada la venta, han de quedar los frutos, rentas, productos y emolumentos de la expresada villa de sueca y su término libres de toda pensión carga o responsabilidad a que estuvieran adictos...» AHMS. Secretaria. Plens. Municipals. Sec. 11. 1801 A 1804

41. En el Acuerdo de 24/01/1803, se incorpora una copia de fecha 18 de enero de 1803 de la Contaduría Principal del Ejército de Valencia, firmada por Agustín del Llano, que a su vez, es copia certificada por D. Bartolomé Muñoz de Torres, escribano de Cámara y Gobierno del Consejo, de fecha 27 de Noviembre de 1802, del original fechado en Tarragona el 14 de noviembre »Está señalado de la Real Mano de S. M.» y dirigido Al Gobernador del Consejo. Original en AGS. Dirección General del Tesoro, inv. 24. legajo 310. folleto 38. sin foliar. Auto de otorgamiento de Escritura de venta de la villa de Sueca a favor del Excmo. Sr. Príncipe de la Paz. Año 1803. AHMS. Secretaria. Plens. Municipals. Sec. 11. 1801 A 1804

42. MAtoses, R.: «Actituds politiques i carrecs municipals al Senyoriu de Sueca 1737-1760», en Quaderns de Sueca, IV. Sueca, 1983, pp. 69-80. 
implantó una fórmula por la que la administración señorial de la Orden de Montesa elegía los cargos de entre una propuesta que realizan los propios oficiales. Este procedimiento incluía dos listas que presentaba el ayuntamiento después de un año en el ejercicio de sus cargos, al Batle o Capitá General de la Universitat de Sueca, a partir de la cual se designaba a los individuos que debían ocupar el año siguiente los oficios del Alcalde Primero y Segundo; los cuatro Regidores; el Síndico; el Alguacil; los dos Alcaldes de Hermandad y el Escribano. No obstante, el hecho que el nombramiento lo realizara el Batle de Sueca y no el órgano directivo de la "Taula de Montesa», seguía dando cierta independencia a la administración municipal. El Batle, cargo que era denominado con el pomposo título de Lloctinent Capitá General $i$ Batle de la Universitat, más comúnmente el Lloctinent de la Senyoria, inicialmente era un miembro más de la comunidad, pero con el devenir del tiempo el cargo fue adquiriendo un carácter más honorífico, limitándose su presencia en la población a los actos protocolarios, nombramientos... o por alguna situación de mayor gravedad para la Orden, en estos casos, mediante la presencia de un sustituto formalmente autorizado. A mediados del siglo XVIII, el título de Batle era ostentado por el Marqués de Cavilles, residente en Madrid, quien nombraba un sustituto o Lugarteniente, que era el que proveía oficialmente el ayuntamiento. ${ }^{43}$

En estas condiciones, el cambio de titularidad del señorío vino a representar un importante retroceso para «vecinos y terratenientes» y para el propio Ayuntamiento. Los enfiteutas actuaban como propietarios a todos los efectos, con la única limitación del pago del correspondiente censo anual, que, gracias al incremento de los precios como consecuencia de la mayor demanda de arroz, era cada vez menos gravoso. La mayor preocupación consistía en la consolidación de sus bienes, como se puede evidenciar por las distintas muestras de conflictividad con Montesa, y el elevado número de pleitos promovidos por el Juez de Apeo y Deslinde, debido a los continuos «aterraments» que trataban de poner en explotación un número cada vez mayor de tierras dedicadas al arrozal ${ }^{44}$.

Godoy, como absoluto y legítimo dueño del Señorío de Sueca, pasaría a ejercer todos los derechos referidos en el Real Decreto. El 4 de marzo de 1803, en un escrito dirigido a los «Srs. Individuos del Ayuntamiento de la Villa de Sueca», les anuncia que como Señor nos toca y pertenece elegir y nombrar en cada un año personas hábiles e idóneas que sirvan los empleos de oficiales y ministros de Justicia. Según se desprende del texto, que incorpora una lista que contiene el nombre de Alcalde, Regidores, Síndicos y Diputados, Godoy, para el año de 1803, concedió la gracia de la continua-

43. AHMS. Sec. Governació: Acuerdos y Resoluciones Capituales No 3. 1737-1739

44. «El establecimiento en enfiteusis de tierras en los límites de la Albufera, no ofrecía en la práctica garantía ninguna sobre la identidad de los predios, lo que juntamente con los abusos, tanto de los que roturaban más allá de sus concesiones, como por la roturación ilegitima de los que sin autorización del intendente se apropiaban de terrenos, originó una gran confusión e inseguridad, por lo que se formó una Instrucción...» Momblanch y GonZalez, F. de P.: Op. Cit... pp. 124. Ver Nota 32. 
ción en los respectivos empleos de estos señores por el presente $a \tilde{n}{ }^{45}$. A pesar de lo anterior, cuatro meses después, el 11 de agosto de ese mismo año, un militar, ajeno a la villa de Sueca, el Capitán Dn. Francisco Xavier Fernández de Trapiella Villaabrile, pasaría a ocupar el puesto de Alcalde Mayor de Sueca, cargo en el que se mantendría hasta su precipitada huida el 20 de marzo de $1808^{46}$.

El príncipe de la Paz -como recoge la documentación municipal- intervendría directamente en la gestión del consistorio, especialmente en aquellas cuestiones que podían afectar directamente a sus intereses ${ }^{47}$. Las notificaciones que Godoy dirigía al Ayuntamiento de Sueca, ofrecían el formalismo de los procedimientos y decretos de gobierno. En los cinco años en que ocupó el Señorío, conseguiría redactar un conjunto de normas, mediante las cuales establecería la designación de cargos y oficios, implantaría procedimientos para regular la actividad agraria, e incluso «legislaría» en materia de orden público ${ }^{48}$. A lo largo de 12 disposiciones «en uso de sus facultades el Serenísimo Sr. Príncipe de la Paz» estableció las normas que debían de regir las penas de Cámara y gastos de Justicia, en las que se indicaba el procedimiento a seguir, las competencias asignadas a cada uno de los intervinientes, las limitaciones, los libros que debían de llevar los escribanos para sentar los temas, los testimonios que con carácter anual se debían de emitir, la prohibición de realizar condenaciones verbales, etc. En el caso de que se faltase a su cumplimiento con sospechosas intenciones, se impondrán las penas y castigos más condignos, según la malicia que se descubriere. A pesar de la advertencia final, esta instrucción no se debía de estar aplicando, ya que el

45. Escrito de 07/03/1803. AHMS. Secretaría. Acuerdos Municipales. Sec. 11. 1801 a 1804.

46. AHMS. Secretaria. Acuerdos Municipales. Caixa 119. Sec. 13. 1807 a 1808.

47. «...Está bien instruido S. Ex a de la practica observada por el Maestrazgo en esa Villa sobre el préstamo del arroz a los cosecheros menesterosos en el tiempo de la sementera: Siendo este un acto voluntario, y de pura generosidad ofrece campo más franco a la bondad, y beneficencia de S. Ex ${ }^{a}$, que nivelara por las verdaderas necesidades y legalmente procederá alejar todo abuso capaz de viciar o impedir el efecto de la rectas intenciones que le animan y de convertir una determinación libre de su voluntad en una obligación forzosa. Por lo demás siempre serán atendidas y remediadas las necesidades de los buenos y honrados labradores de ese su Pueblo con mano franca y con la circunspección que exigen la prudencia, la justicia y la utilidad pública. Téngalo VVms. así entendido para concurrir por su parte al acierto...» Escrito de 03/03/1803. En el mes de octubre de 1803 adopta una serie de acuerdos, que en teoría pretenden poner orden y control en los sectores marginales de la población, que iban pidiendo limosna por las partidas de tierra de arroz, secaderos e incluso dentro del casco urbano. Se llega a justificar el prejuicio de los derechos diezmales que afecta al señorío, que es la última y auténtica causa de estos decretos que prohíben la mendicidad. AHMS. Secretaría. Acuerdos Municipales. Sec. 11. 1801 a 1804.

48. El 19 de noviembre de 1804, Godoy, hace llegar al Ayuntamiento sus «Instrucciones sobre las penas de Cámara para Gobierno de la Villa de Sueca... a quienes toque, o tocar pueda. Sabed: que enterado de la obscuridad y falta de orden, con que se administra en esa mi Villa el Ramo de Penas de Cámara, campo y Riego, y gastos de Justicia, y perteneciéndome en fuerza de los pactos, con que adquirí ese Señorio, sancionados por S. M. no solo la percepción de esos frutos de mi Jurisdicción en esa, sino también la facultad de arreglar su recaudación administración e inversión legitima, he tenido a bien en uso de mis facultades ordenar y establecer la siguiente instrucción.» AHMS. Secretaria. Plens. Municipals. Caixa 119 Sec. 13.1807 a 1808. 
5 de enero de 1808, José Nebot, administrador de Godoy se dirigía al Ayuntamiento de Sueca recordando el contenido de la Instrucción, dado su incumplimiento ${ }^{49}$.

En la totalidad de los escritos formulados por Godoy al pueblo de Sueca subyace la intención de persuadir a sus nuevos «vasallos», de lo conveniente y beneficioso que va a resultar para ellos el cambio de dependencia señorial. Se trata de convencer a los vecinos de Sueca, de que el hecho de que el nuevo Señor sea el todopoderoso Príncipe de la Paz les va a resultar más ventajoso ${ }^{50}$.

Este paternalismo sería aprovechado por los enfiteutas, quienes con motivo de una protesta por la partición de frutos que trasladaron al nuevo dueño del señorío, en un ejercicio de precaución, se vino a insistir en dejar clara la idea de que quien estaba realizando abusos eran los administradores, los funcionarios señoriales y no el propio señor a quien se recurre como representante de la justicia y como "padre» desconocedor de las medidas que se llevan a cabo en su señorío. Al tiempo que se le pedía que ordenara lo que creyera más oportuno, se aprovechaba para llamar su atención sobre la importancia de las rentas que cobraba, y gracias a quién las cobra$\mathrm{ba}^{51}$. Aparentemente, se quería dejar constancia de que se había asumido la condición de vasallo, por tanto se remarca la actitud de obediencia y de sumisión a la voluntad de Godoy, pero también se le hacía ver, que sabían sin ninguna opción de duda, que se les pretendía cobrar más de lo estrictamente estipulado. En ocasiones, esta táctica sumisa por parte de los enfiteutas dio resultados, ya que Godoy admitió finalmente que de momento se siguiese partiendo los frutos del mismo modo que se hacía con el administrador de Montesa; si bien en lo sucesivo quedó sobradamente demostrado que el nuevo señor estaba dispuesto a aumentar por todos los medios la rentabilidad de sus tierras y derechos.

El 9 de marzo de 1804, el Príncipe de la Paz fundó el Mayorazgo del Ducado de Sueca, en escritura otorgada ante el escribano Tomás de Sancha y Prado. Godoy instituía el Mayorazgo «animado del natural deseo de perpetuar su nombre» y lo logró usando de las Reales facultades que para ello le habían sido concedidas por el Rey. El

49. «...aunque se comunicó y se publicó, se ha notado en el examen de las cuentas presentadas la inobservancia, tal vez por no haberse quedado los escribanos con copia de ella. Me ha parecido, pues, remitírselas a cada uno consignadas, e igualmente a ese Ayuntamiento para que se coloque en el libro de las ordenes, contestándome a haberse así executado y leido para inteligencia de los individuos de él.» AHMS. Secretaria. Plens. Municipals. Caixa 119 Sec. 13. 1807 a 1808.

50. «... y así como VV. Se proponen una exacta obediencia a Mis Ordenes en comprobación de su lealtad, asi Yo solo haré uso de mi autoridad y facultades en quanto puedan contribuir a la felicidad común y particular de ese Mi Pueblo y sus Moradores...» Escrito de Godoy de 09/03/1803. AHMS. Secretaría. Acuerdos Municipales. Sec. 11. 1801 a 1804.

51. «...resuelva y determine lo que fuese de su mayor agrado y su benéfico corazón. le dicte para unos que con su sudor y afanes rinden a V.E. la renta anual de cuarenta y dos mil pesos, con las tierras de término particular de esta villa y con el de las de su frontera de la Albufera...» AHMS. Secretaría. Acuerdos Municipales. Sec. 11. 1801 a 1804. 
Mayorazgo tenía carácter de perpetuo, de sucesión regular ${ }^{52}$, dotándole con el Ducado de Alcudia, Grandeza de España, dehesas y bienes anexos; con el Soto de Roma; con el Ducado de Sueca y todas sus pertenencias ${ }^{53}$. La presión señorial fue en aumento. Godoy trató por todos los medios, no solo de alcanzar los niveles de privilegio de los que gozaban los administradores del Maestrazgo de Montesa ${ }^{54}$, sino incluso de incrementarlos en todo aquello que le pudiera reportar mayores fuentes de ingresos. Frente a lo anterior, la posición de los vecinos y terratenientes sería la de rechazo a cualquier avance de consolidación de los derechos señoriales, lo que derivaría en continuos conflictos.

\section{A MODO DE EPÍLOGO}

La noticia de la confiscación de los bienes de Godoy fue recibida con gran entusiasmo por la población de Sueca. El mismo 20 de marzo de 1808, finalizados los sucesos provocados por el Motín de Aranjuez ${ }^{55}$, que había forzado la dimisión de Carlos IV, el nuevo rey Fernando VII encargaba al Consejo de Castilla llevar a efecto la confiscación de los bienes del Príncipe de la $\mathrm{Paz}^{56}$. Esta decisión daba solución a los problemas de los vecinos, terratenientes y al propio consistorio de Sueca.

52. En la creación del Mayorazgo llamaba a su disfrute a su descendencia legítima y a falta de ella a la de varios hermanos. Belmonte díaz, J. y Leseduarte Gil, P.: $O p$, Cit..., pp 76-77. La Parra. E.: $O p$. Cit... pp. 258

53. El título de Duque de SUECA, con Grandeza de España de Primera clase fue concedido a Manuel Godoy, por Carlos IV, mediante una Real Decreto de 18/12/1803. En el mismo se establecía la facultad para fundar un mayorazgo del Ducado de la Alcudia y otro por vía de agregación al mismo, al que pudiere unir la villa de Sueca con el lago de la Albufera y otros bienes. AHNS, Fons Antics. 111. Llibre 327. Sig. A1-E14. Exposición del Ayuntamiento de Sueca a la Cortes Constituyentes pidiendo aclaración de las leyes vigentes sobre Señoríos. Imprenta de los Dos Reinos. Valencia. 1870. pp 6-7.

54. «... Por quanto me toca, y pertenece elegir y nombrar en cada un año persona hábil, é idónea que exerza las funciones y cargo... y estando bien informado de las buenas prendas y circunstancias que para este efecto concurren... he venido en nombraros y elegiros por el presente os elijo y nombro...» Como muestra de lo anterior, el 5 de diciembre de 1807 el Príncipe de la Paz remitía el nombramiento de los cargos de Cequiero Mayor y Justicia para el año 1808 AHMS. Secretaria. Plens. Municipals. Caixa 119. Sec. 13.1807 a 1808.

55. «...En la corte, el palacio de Godoy fue saqueado; los muebles, arrojados por las ventanas, sirvieron para hacer una hoguera en la calle, violencias se repitieron en los domicilios de sus parientes y amigos, colaboradores y protegidos...». ARTOLA Gallego, M.: La España de Fernando VII. Espasa-Calpe: Ministerio de Educación y Ciencia. Madrid. 1999-1968, pp. 41.

56. «Habiendo confiscado en nombre de S. M. (que Dios guarde) en virtud de la orden con que me hallo autorizado de los Estados de la Albufera y Sueca, bienes, fincas y efectos que pertenecieron en ellos a $D^{n}$. Manuel de Godoy, debo formar un prolijo inventario de todo, pero como para executarle exige la gravedad del negocio se tomen individuales, y exactas noticias, interin ellas se adquieren, he creído necesario comunicarlo a VM, para su inteligencia, debiendo añadir que por ahora recaudaran y administraran dichos estados $D^{n}$.Josef Nebot...pero a nombre de S. M. y a disposición de los Señores que componen la Junta nombrada por el Supremo Consejo para entender en la confiscación...» AHMS. Secretaria. Plens. Municipals. Caixa 119. Sec. 13. 1807 a 1808. El 10 de abril el «Diario de Valencia» publicaba un aviso firmado por D. Bartolomé Muñoz, el día 2 del mismo mes en el que «se hacía saber a cuantas personas tuviesen en su poder o conocieran el paradero de dinero, alhajas, bienes, derecho u otros efectos pro- 
Unos días después, el primero de abril de 1808, se reunió el Ayuntamiento de Sueca en un pleno extraordinario, que debido a la precipitada ausencia del Alcalde Mayor, fue presidido por Josef Yborra Burgos, Regidor Decano. De acuerdo con el Regente de la Real Audiencia de Valencia, se otorgaron facultades al Regidor, para entender lo relativo a los Estados de la Albufera y de esta Villa, en virtud de la Confiscación a todos los efectos pertenecientes a D. Manuel Godoy en los que esta comprenda esta Jurisdicción acompañándose testimonio de este Acuerdo.» ${ }^{57}$

En los meses inmediatamente posteriores, se produjo una rápida sucesión de los acontecimientos. El viaje a Francia de toda la familia real, incluido el propio Godoy; las abdicaciones de Carlos IV y Fernando VII en Bayona, el 8 de mayo de 1808; la decisión de Napoleón de elevar al trono de España a su hermano José I. Todos estos sucesos abrieron un dilatado paréntesis, en el que Sueca y la Albufera, sufrirían un nuevo cambio de jurisdicción, el cuarto en menos de una década ${ }^{58}$. El Ayuntamiento, con la salida de las tropas de Suchet, intentaría de nuevo recuperar estas propiedades e incorporándolas a los bienes de propios municipales, amparándose en el texto Decretado en Cádiz de 6 de Agosto de 1811. A lo largo de estos años, con cada nuevo triunfo liberal, y el regreso a la Constitución de Cádiz, se tratará de obtener la posesión y el control de las regalías. ${ }^{59}$ Pero, con cada regreso al sistema de gobierno absolutista, se producirían múltiples requerimientos al Consistorio suecano, para que se hicieran efectivas las rentas pendientes. Los escritos de las diferentes instituciones, fueron sor-

pios pertenecientes por cualquier título a D. Manuel Godoy, que debían entregarlos o denunciarlos a la mayor brevedad...» Momblanch Y GonCÁlBeZ, F. de P.: Op. Cit... pp. 128.

57. Acuerdo Extraordinario de fecha 01/04/1808. AHMS. Secretaria. Acuerdos Municipales. Caixa 119. Sec. 13. 1807 a 1808 .

58. El decreto del 24 de enero de 1812, por el que Napoleón otorgaba el título de Duque de la Albufera al Mariscal Suchet, tuvo consecuencias para Sueca: por unos meses, la capital de la Ribera Baixa, pasó a depender del general francés. El nuevo titular incorporó cambios en la administración del consistorio municipal y en el señorío, con su consiguiente incidencia en las relaciones de vecinos y terratenientes, transitoriamente unidos por la defensa de sus intereses económicos, en el objetivo común de la abolición del régimen señorial. RosAdo CALATAYUD, L.: «Louis Gabriel Suchet Mariscal del Imperio y Duque de La Albufera. Efímero Señor de Sueca (1812-1813)» Actas del Congreso Internacional sobre la Guerra de la Independencia y los cambios institucionales. Universidad CEU Cardenal Herrera. Valencia. Diciembre 2007. Diputación de Valencia. 2009., pp. 137-152

59. «...Por el decreto de las Cortes de seis de agosto de 1811 sancionado por S.M., han quedado abolidos algunos de los derechos comprendidos en dicho arriendo; y los pueblos fundados en el mismo decreto se han negado y niegan abiertamente el repartimiento y pago de frutos...». El impago de los censos y rentas llevó incluso a que los arrendatarios de los bienes de propios, solicitaran la rescisión del contrato por la falta de ingresos, por la abierta negativa al pago y la oposición antiseñorial de los vecinos, ya que estos consideraban suspendidas las prestaciones señoriales y enfitéuticas según el decreto de seis de agosto de 1811. Durante el Trienio Liberal, la resistencia antiseñorial presenta en Sueca, una doble incidencia: la lucha contra los derechos señoriales, general a todo el Estado, y la especial situación de este señorío caracterizado por la notable fuerza y resistencia de los enfiteutas. ARV. Propiedades Antiguas. Leg. 729. 
teados con grandes dosis de habilidad, aprovechando todos los resquicios legales que suponían dilación de plazos y que permitían ganar tiempo ${ }^{60}$.

En junio de 1828 se produjo un giro en la situación y un nuevo cambio de titularidad del Señorío de Sueca, como consecuencia de la solicitud de revisión que María Teresa de Borbón, esposa de Godoy, y prima de Fernando VII, había realizado ante los tribunales en 1821, con el fin de determinar los derechos que asistían a su hija Carlota, en relación con los bienes confiscados a Godoy. Esta solicitud, en junio de 1828 vio cumplidos sus propósitos, determinando finalmente que entre los bienes correspondientes a la Condesa de Chinchón se encontraba el Señorío de Sueca. María Teresa fallecería en noviembre de ese mismo año, quedando como única heredera Carlota Luisa Godoy y Borbón, que por real orden de julio de 1830 le fue concedida la propiedad del Señorío de Sueca. Como consecuencia de la ley de 26 de agosto de $1837^{61}$, el Ayuntamiento inició un pleito con los herederos de Godoy que se prolongó hasta el día 10 de noviembre de $1873^{62}$, momento en que se obtuvo una sentencia favorable para el consistorio de Sueca.

60. Los diferentes oficios responsabilizan al Ayuntamiento de la demora en el pago de los derechos. Oficio Intendencia Ejército de 09/06/1823. Oficio Intendencia del Crédito Público de 09/07/1823; 05/09/ 1823 y 18/09/1823: Oficio del Comisionado Subalterno de Alcira de 19/07/1823: AHMS. Secretaria. Plens. Municipals Sec. 16.

61. Exposición del Ayuntamiento de Sueca a la Cortes Constituyentes pidiendo aclaración de las leyes vigentes sobre Señoríos. Imprenta de los Dos Reinos. Valencia. 1870. pp. 7-8.

62. «...El Gobierno de la República, reunidos en Consejo de Ministros y a propuesta del Ministerio de Hacienda, decreta: Artículo $1^{\circ}$.- Se declaran bienes de la Nación todos los pertenecientes al secuestro de don Manuel Godoy... El presidente del Gobierno de la República. Emilio Castelar...» AHMS. Gaceta de Madrid. 18/11/1873. Ministerio de Hacienda. 